Canadian

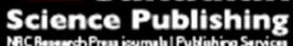

Canadian Journal of Microbiology Revue canadienne de de microbiologie

\title{
Influence of Water Quality on Nitrifier Regrowth in Two Full-scale Drinking Water Distribution Systems
}

\begin{tabular}{|r|l|}
\hline Journal: & Canadian Journal of Microbiology \\
\hline Manuscript ID & cjm-2015-0375.R1 \\
\hline Manuscript Type: & Article \\
\hline Date Submitted by the Author: & 28-Sep-2015 \\
\hline Complete List of Authors: & $\begin{array}{l}\text { Scott, Daniel B.; University of Waterloo, Civil and Environmental } \\
\text { Engineering } \\
\text { Van Dyke, Michele I.; University of Waterloo, Civil \& Environmental } \\
\text { Engineering } \\
\text { Anderson, William B.; University of Waterloo, Civil and Environmental } \\
\text { Engineering } \\
\text { Huck, Peter M.; University of Waterloo, Civil and Environmental } \\
\text { Engineering }\end{array}$ \\
\hline Keyword: & $\begin{array}{l}\text { chloramine, distribution system, drinking water, nitrifier, ammonia- } \\
\text { oxidizing }\end{array}$ \\
\hline
\end{tabular}

SCHOLARONE $^{\mathrm{m}}$

Manuscripts 
1

3

4

Influence of Water Quality on Nitrifier Regrowth in Two Full-scale Drinking Water

$$
\text { Distribution Systems }
$$

5

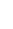
NSERC Chair in Water Treatment, Department of Civil and Environmental Engineering,

Daniel B. Scott ${ }^{\dagger}$, Michele I. Van Dyke*, William B. Anderson and Peter M. Huck (1)

$8 \quad{ }^{*}$ Corresponding author. 200 University Avenue West, Waterloo, Ontario, Canada N2L 3G1.

$9 \quad$ Tel: 519-888-4567 ext. 36193, Email: mvandyke@uwaterloo.ca.

William B. Anderson, wbanderson@uwaterloo.ca

Peter M. Huck, pm2huck@uwaterloo.ca

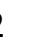

${ }^{\dagger}$ Current address: ADI Systems Inc., Fredericton, New Brunswick, Canada.

Email: daniel.b.scott@adi.ca 


\section{ABSTRACT}

The potential for regrowth of nitrifying microorganisms was monitored in two full-scale

17 chloraminated drinking water distribution systems in Ontario, Canada, over a nine month period.

18 Quantitative PCR was used to measure amoA genes from ammonia-oxidizing bacteria (AOB) and ammonia-oxidizing archaea (AOA), and these values were compared with water quality

20 parameters that can influence nitrifier survival and growth including total chlorine, ammonia, temperature, $\mathrm{pH}$, and organic carbon. Although there were no severe nitrification episodes, AOB

22 and AOA were frequently detected at low concentrations in samples collected from both

23 distributions systems. A culture-based presence/absence test confirmed the presence of viable

24 nitrifiers. AOB were usually present in similar or greater numbers than AOA in both systems. As

25 well, AOB showed higher regrowth potential compared with AOA in both systems. Statistically

26 significant correlations were measured between several water quality parameters of relevance to

27 nitrification. Total chlorine was negatively correlated with both nitrifiers and heterotrophic plate count (HPC) bacteria, and ammonia levels were positively correlated with nitrifiers. Of particular

29 importance was the strong correlation between HPC and AOB, which reinforces the usefulness

30 of HPC as an operational parameter to measure general microbiological conditions in distribution 31 systems.

KEYWORDS: ammonia-oxidizing, chloramine, distribution system, drinking water, nitrifier. 


\section{INTRODUCTION}

Monochloramine is used as a secondary disinfectant by many drinking water utilities in North America due to its lower potential for forming disinfection by-products (DBPs), longer persistence in distribution systems, and improved biofilm penetration compared with free chlorine (LeChevallier et al. 1990; Zhang and Edwards 2009). However, the presence of ammonia can also promote the growth of nitrifiers, which can lead to operational or regulatorycompliance challenges including a decline in the disinfectant residual, increased biofilm production and corrosion. Nitrification is a widespread issue in chloraminated drinking water distribution systems. For example, Wilczak et al. (1996) found that two thirds of U.S. utilities that applied chloramination experienced some degree of nitrification.

Ammonia-oxidation, the first and rate-limiting step of nitrification (Francis et al. 2005), is performed by autotrophic microorganisms from Bacteria (ammonia-oxidizing bacteria, AOB) and Archaea (ammonia-oxidizing archaea, AOA). This first step of nitrification is of concern in distribution system environments (Skadsen 1993; Lipponen et al. 2002) and is the subject of the present research. Some free ammonia will typically be available to ammonia-oxidizing microorganisms in treated water, and this amount will increase as monochloramine undergoes decay in the distribution system. This creates a positive feedback loop, since nitrification products (nitrite, and increased organic matter from nitrifier growth) accelerates chloramine decay, providing more free ammonia, and thus further promoting the growth of nitrifying microorganisms (Oldenburg et al. 2002). Factors that can affect distribution system nitrification include ammonia concentration, monochloramine concentration, temperature, dissolved oxygen (DO), $\mathrm{pH}$, and organic carbon levels (Zhang et al. 2009). 
Consequences of distribution system nitrification include an accelerated decay of the

57 chloramine residual, a rise in nitrite and/or nitrate concentrations, and the potential for an

58 increase in heterotrophic bacteria levels, and these have been recommended as indicators that

59 nitrification is occurring (Odell et al. 1996; AWWA 2006). The consequences of nitrification are not likely to be a direct risk to public health; rather, they may lead to operational or regulatory-

61 compliance challenges. However, a loss of the disinfectant residual can potentially decrease the

62 robustness of the distribution system as the final barrier for safe drinking water before it is

63 delivered to consumers (Health Canada 2002).

In this study, water samples were collected from two full-scale chloraminated distribution

65 systems in southern Ontario, and parameters relevant to nitrification were monitored. The

66 potential for regrowth of both $\mathrm{AOA}$ and $\mathrm{AOB}$ was measured using quantitative PCR assays that

67 target the $a m o A$ gene. The amo $A$ gene encodes subunit A of the ammonia monooxygenase

68 enzyme, required for the oxidation of ammonia to hydroxylamine. The traditional technique for

69 enumerating nitrifying bacteria is the culture-based most probable number (MPN) method

70 (Standard Methods 2005). However, culture-independent techniques are more rapid and accurate

71 than culture-based methods because nitrifiers are very slow-growing and growth media shows

72 some selectivity (i.e. Hoefel et al. 2005). Molecular techniques have been used to assess the

73 relative occurrence of $\mathrm{AOA}$ and $\mathrm{AOB}$ in various environments, but few studies have applied

74 these methods to drinking water (de Vet et al. 2009; van der Wielen et al. 2009; Kasuga et al.

75 2010b). The correlation between nitrifier concentrations and potential indicators or predictors of 76 nitrification was also evaluated.

77

78 MATERIALS AND METHODS 


\section{Systems studied}

The water utilities of the City of Toronto (Toronto Water) and the Region of Waterloo participated in this study. Both systems are located in southern Ontario, Canada, and use monochloramine as a secondary disinfectant. The Toronto Water distribution system is served by four water treatment plants that draw raw water from Lake Ontario. The plant that serves the part of the distribution system included in this study is a conventional water treatment plant with a capacity of $615 \mathrm{ML} / \mathrm{d}$. The process train includes pre-chlorination (for zebra mussel control), coagulation, flocculation, sedimentation, dual-media (anthracite/sand) filtration, and chlorine disinfection, followed by chloramination for secondary disinfection. The Region of Waterloo distribution system is served by a blend of surface water $(27 \%)$ and groundwater $(73 \%)$, and these combined sources have a capacity of $72 \mathrm{ML} / \mathrm{d}$. The distribution system included in this study receives surface water from the Grand River, and the process train at the treatment plant consists of coagulation, flocculation, sedimentation, ozonation, multi-media filtration, UV disinfection, and chlorine disinfection, followed by chloramination for secondary disinfection. Treated surface water is blended with groundwater prior to entering the distribution system. The groundwater was treated using either UV or chlorine for primary disinfection, followed by chloramines for secondary disinfection. Table 1 summarizes the average values of the physicalchemical parameters measured over the course of the study at the entrance to each distribution system (sites T-WTP and W-WTP). The DOC concentration, conductivity, background nitrate levels and temperature range were higher in Waterloo, whereas the values for the other parameters were similar.

Sample sites used in the study were spatially dispersed, had some historical differences in total chlorine and heterotrophic plate count (HPC) concentrations, and were used by each utility 
102 as part of their regular monitoring program. Sample sites in the Toronto Water distribution

103 system included one treatment plant (T-WTP) and 6 locations in the distribution system (T-1 to

104 T-6), and 12 samples were collected from each site (approximately every 2-4 weeks from

105 November 2009 to August 2010). Sample sites in the Region of Waterloo included the treatment 106 plant (W-WTP) and 7 locations in the northern area of the regional distribution system (W-1 to

107 W-7), and 9 samples were collected from each site (every 2-4 weeks from February to August 108 2010). Site W-5 was near a free chlorine booster station and thus had a free chlorine residual 109 instead of a chloramine residual. The distance between each distribution system site and the 110 drinking water treatments plant increased with increasing sample designation.

\section{Physical-chemical analyses}

Samples collected at the treatment plants were taken from continuous-flow sampling taps.

114 Distribution system samples were taken after the taps were flushed to a steady water temperature.

115 Temperature, conductivity, $\mathrm{pH}$ and chlorine were measured on site. Temperature and

116 conductivity were measured with a Hach CO150 conductivity meter, and pH with an Orion 290A

$117 \mathrm{pH}$ meter with an $\mathrm{Ag} / \mathrm{AgCl}$ electrode probe. Total chlorine was analyzed by Hach method 8167

118 (Hach 2008), which is based on Standard Method 4500-Cl G. Samples for further analyses (DOC,

119 ammonia, nitrite, nitrate) were collected in $300 \mathrm{~mL}$ glass bottles and transported to the lab on ice.

120 Samples for DOC and ion chromatography were filtered through a $0.45 \mu \mathrm{m}$ Pall Supor 450

121 membrane filter and stored at $4{ }^{\circ} \mathrm{C}$ until analysis. DOC was quantified by automated wet

122 oxidation (OI Analytical 1010), and nitrite and nitrate using a Dionex ICS-series ion

123 chromatograph with an AS4A-SC $4 \mathrm{~mm}$ anion exchange column. Monochloramine and free

124 ammonia were measured according to Hach method 10200 (Hach 2008). 


\section{Microbiological analyses}

Distribution system samples for microbiological analyses were collected before the tap was flushed, and although this was a departure from standard sampling procedures (Method 9060

A, Standard Methods 2005), it was considered more appropriate for this study because it provided a better measure of microbial regrowth and biofilm formation potential. In addition, stagnant water represents a more critical condition for nitrification, and thus was of greater interest in this project. Samples for nitrifier analysis were collected in sterile $1 \mathrm{~L}$ plastic bottles containing $1 \mathrm{~mL}$ of $3 \%$ sodium thiosulfate to quench the disinfectant residual. A separate 250 $\mathrm{mL}$ water sample collected in a sterile bottle containing sodium thiosulfate (Systems Plus, Baden, ON) was taken for HPC. Sample bottles were transported on ice, held at $4{ }^{\circ} \mathrm{C}$ and analyzed within $48 \mathrm{~h}$. For HPC analysis, $1 \mathrm{~mL}$ and $10 \mathrm{~mL}$ volumes were separately passed through a sterile 0.45

$137 \mu \mathrm{m}$ Pall GN-6 membrane filter by vacuum filtration, placed on R2A agar and incubated at $28^{\circ} \mathrm{C}$ 138 for 5-7 days. Colonies were then counted at 20× magnification. This method is based on 139 Standard Method 9215 (Standard Methods 2005).

141 enumerated by quantitative PCR (qPCR) of the amo $A$ gene. One L of each sample was 142 concentrated by vacuum filtration through a sterile $0.2 \mu \mathrm{m}$ Pall Supor 200 membrane filter. Each 143 filter was placed in a $3 \mathrm{~mL}$ plastic vial containing $1.5 \mathrm{~mL}$ of GITC buffer (Cheyne et al. 2010) 144 and frozen at $-80^{\circ} \mathrm{C}$. Samples were then subjected to three freeze-thaw cycles $\left(-80^{\circ} \mathrm{C}\right.$ followed by $14550^{\circ} \mathrm{C}$ for 15 minutes), followed by DNA extraction and purification as described by Cheyne et al. 146 (2010). qPCR was performed using AOB primers that target the $\beta$-Proteobacterial group of 147 ammonia-oxidizing bacteria as described by Rotthauwe et al. (1997) and AOA primers that 
148 target strains from the domain Archaea as described by de la Torre et al. (2008). Each $50 \mu \mathrm{L}$ 149 PCR reaction contained $20 \mu \mathrm{L}$ of concentrated DNA (corresponding to $200 \mathrm{~mL}$ of distribution system sample), $300 \mathrm{nM}$ of each primer, $25 \mu \mathrm{L}$ of 2x SsoFast EvaGreen Supermix (BioRad), and

$15120 \mu \mathrm{g}$ BSA (Sigma). The cycling conditions for the AOA assay were 1 cycle at $95^{\circ} \mathrm{C}$ for 2

152 minutes; 40 cycles at $95^{\circ} \mathrm{C}$ for $15 \mathrm{~s}, 54^{\circ} \mathrm{C}$ for $30 \mathrm{~s}$ and $72^{\circ} \mathrm{C}$ for $60 \mathrm{~s}$. The same conditions were 153 used for the AOB assay, but with an annealing temperature of $59^{\circ} \mathrm{C}$. PCR templates used $a m o A$ 154 genes cloned into the pCR 4-TOPO vector (Invitrogen). The bacterial amo $A$ gene was obtained 155 from a pure culture of Nitrosomonas europaea. The archaeal amoA gene was amplified from a 156 river water sample. The vector was linearized using the PstI enzyme, and template 157 concentrations were determined using the Quant-iT PicoGreen kit (Invitrogen). The specificity of 158 each PCR reaction was confirmed by melt curve analysis and agarose gel electrophoresis.

A culture-based detection method for ammonia-oxidizing bacteria based on Standard Method 9245 (Standard Methods 2005) was applied to samples collected from the Toronto 161 distribution system on 17 August 2010, and to samples collected from the Region of Waterloo distribution system on 25 August 2010. One L of each sample was filtered through a $0.2 \mu$ m Pall Supor 200 membrane. The membrane was then placed in $50 \mathrm{~mL}$ of growth media and incubated at $28^{\circ} \mathrm{C}$ for 28 days. The media was tested for nitrite and nitrate using the Hach NitriVer and NitraVer reagents. Samples with detectable nitrite $(>0.002 \mathrm{mg} / \mathrm{L}$ as N$)$ and nitrate $(>0.1 \mathrm{mg} / \mathrm{L}$ as $\mathrm{N}$ ) were considered positive for ammonia-oxidizing microorganisms.

\section{Data analyses}

Statistical analysis was performed using the software "R" (R Development Core Team 2009). The relationship between distribution system parameters was determined using the non- 
171 parametric Spearman correlation coefficient $(\rho)$. The Spearman correlation coefficient is often

172 used in distribution system research (Cunliffe 1991; Rice et al. 1991; Lipponen et al. 2002, 2004)

173 when the parameters measured are not normally distributed or have a large number of values

174 below the detection level. To determine if the correlation between certain parameters was due to 175 their mutual correlation with a third factor, partial correlation coefficients were calculated. The

176 Kruskal-Wallis test was used to determine if there was a difference in nitrifier concentrations 177 between sites. Significant differences in nitrifier and HPC concentrations between water leaving 178 the treatment plants (T-WTP and W-WTP) and each distribution system site were measured 179 using the Mann-Whitney U test $(\mathrm{p}<0.05 ; 2$ tailed).

\section{RESULTS AND DISCUSSION}

\section{Occurrence of nitrifying microorganisms}

Few studies (van der Wielen et al. 2009; Kasuga et al. 2010b, 2010a; Wang et al. 2014)

have examined both $\mathrm{AOB}$ and AOA in drinking water. Since most existing information on ammonia-oxidizing microorganisms is for bacteria (AOB), the occurrence of AOA in

186 distribution systems is of interest, as they may have different growth and survival properties. For 187 example, Martens-Habbena et al. (2009) found a half-saturation coefficient for ammonia in a 188 strain of AOA that was lower than any reported for AOB, suggesting that some AOA strains may 189 be better adapted for growth at low ammonia concentrations. According to Kasuga et al. (2010b), 190 AOA and AOB might differ in their resistance to chlorine. Indeed, questions on the relative 191 abundance and respective roles of AOA and AOB in nitrification have been topics of recent 192 research (Hatzenpichler 2012; Prosser and Nicol 2008; Schleper 2010). 
This study used a PCR approach targeting the amoA genes of either AOB or AOA to

detect putative ammonia-oxidizing microorganisms in two chloraminated drinking water distribution systems. PCR assays that target the amo $A$ gene are frequently used in environmental studies, since conserved but distinct groups of this functional gene have been detected in bacterial and archaeal microorganisms (Francis et al. 2005). To date, AOA strains have been shown to contain one copy of the gene (Hatzenpichler 2012), while AOB strains have between 2 to 3 copies (Norton et al. 2002). By using a gene that encodes a key metabolic enzyme, assays have certain advantages over phylogenetic markers including improved specificity and sensitivity (Junier et al., 2010). Results showed that amo $A$ genes from both groups of ammoniaoxidizing microorganisms were frequently detected in samples collected from the two systems (Figures 1 and 2). The data are summarized as boxplots, showing the median and central 50\% (interquartile range), with whiskers that extend to the minimum and maximum values. Sample sites are ordered on the $\mathrm{x}$-axis according to distance from the water treatment plant (WTP), but the cumulative hydraulic retention time for each site was not available.

In the Waterloo distribution system, $\mathrm{AOB}$ and $\mathrm{AOA}$ concentrations were significantly correlated (Table 2). Site W-5 was located by a reservoir with a free chlorine booster station, and therefore was the only site to use free chlorine and not chloramines. W-5 had low levels of both types of ammonia-oxidizing microorganisms relative to other sites, showing that nitrification is an issue primarily when chloramines are used as a disinfectant. In the Toronto system, AOB were typically more numerous than AOA, and the concentration of the two groups was not correlated (Table 2). AOA concentrations following treatment at Waterloo were consistently higher than at Toronto, presumably due to higher source water concentrations. However, nitrifiers in the raw water were not measured in this study. 
In both systems, AOB concentrations increased from low levels in water leaving the

217 treatment plants to 2-3 log higher concentrations at sites in the distribution system. This increase

218 was significant at each site (except W-5) in both the Toronto and Waterloo systems (Figure 1).

219 However, AOA did not show the same regrowth potential. There were increases in the AOA

220 concentration (up to $1 \mathrm{log}$ ) at some sites, and in Toronto this increase was significant at sites T-2

221 and T-4, and in Waterloo at sites W-1, W-3 and W-4 (Figure 2). Overall, the increase in AOB

222 from the entrance to each distribution system to the site with the highest median value was

223 greater than the increase in AOA. This suggests that AOB may be better adapted for growth in

224 distribution systems. Further research is recommended to investigate differences between the

225 optimal niches for AOB and AOA, and whether there is any difference in their roles in

226 distribution system nitrification.

227 To complement the nitrifier occurrence data obtained from qPCR of the amo $A$ genes, a

228 culture-based test for ammonia-oxidizing microorganisms was also employed. This was done

229 because PCR detects intact DNA from both live and dead cells, whereas a culture-based test will

230 only measure if viable cells are present. Table 3 shows that for samples collected on a day with

231 typical water quality, the majority of sites were positive for autotrophic ammonia-oxidation,

232 indicating that viable ammonia-oxidizing microorganisms were present. However, it is possible

233 that the concentration of amoA genes detected by PCR was influenced by the presence of dead

234 cells, since the samples were taken following water treatment processes that included

235 disinfection.

236

237 Relationship between nitrifiers and water quality parameters 
Water quality parameters were monitored in both full-scale distribution systems, and the relationship between these parameters and nitrifier concentrations was determined (Table 2). This information is useful for understanding conditions that can influence nitrifier survival and growth in drinking water systems. In addition, this assessment can identify if factors that are

242 easily and routinely measured in drinking water systems can predict nitrifier occurrence and 243 potential nitrifying conditions.

General microbiological water quality is typically measured in drinking water using the HPC method (National Research Council 2006; Health Canada 2012), and it has been suggested that an increase in HPC bacteria may be associated with nitrification (Skadsen 1993; Odell et al. 1996; Wilczak et al. 1996; Zhang et al. 2009). Two mechanisms by which nitrification can

248 promote the growth of heterotrophic bacteria are (1) accelerating the decay of the disinfectant residual and (2) increasing organic carbon availability through the formation of soluble microbial 250 products (SMP) (Rittmann et al. 1994). Figure 3 shows HPC levels measured at the entrance to 251 each distribution system were low (less than 1 CFU per mL on most sampling dates), and that 252 HPC concentrations were 1-2 log higher in distribution system samples. This suggests that 253 conditions were favorable for bacterial regrowth in both distribution systems. The site with a free 254 chlorine residual (W-5) had HPC levels similar to nearby sites, whereas AOB and AOA 255 concentrations at W-5 were much lower than at nearby chloraminated sites. This suggests that 256 nitrifier regrowth was controlled by limitation of the ammonia substrate, and not by disinfection 257 with free chlorine, which would have had a similar effect on HPC. and therefore partial correlation coefficients were calculated to determine if the correlation 
261 between AOB and HPC was due to their sensitivity to chlorine. The partial correlation

262 coefficients of AOB and HPC with total chlorine as the third factor were 0.48 and 0.54 for

263 Toronto and Waterloo, respectively (results not shown). Since these partial correlation

264 coefficients were similar to the original values ( 0.51 for Toronto and 0.58 for Waterloo), the

265 correlation between AOB and HPC was not a statistical artefact of their mutual correlation with

266 total chlorine. However, HPC levels were not correlated with AOA in either system (Table 2).

267 This suggests that factors affecting survival and regrowth of AOB and HPC in the distribution 268 systems did not similarly promote regrowth of AOA.

269 The fact that HPC and AOB were correlated reinforces that HPC is a good indicator for 270 the regrowth of nitrifying bacteria. Although there was some loss of DOC after each WTP (12$271 \quad 16 \%$ in Toronto, $22-37 \%$ in Waterloo), there was no correlation between DOC and HPC or 272 nitrifiers (Table 2). However, DOC levels may not have been correlated with the fraction of 273 organic carbon that is readily available to microorganisms (i.e. assimilable organic carbon 274 (AOC)). A correlation between nitrifying bacteria and heterotrophic bacteria has been previously 275 observed in bulk water samples (Lipponen et al. 2002) and biofilms (Lipponen et al. 2004).

276 Health Canada (2012) favours HPC as a useful operational parameter to monitor general

277 bacteriological water quality, including bacterial regrowth, and this study provides support for 278 that position. HPCs have also been recommended as a possible nitrification indicator by Zhang et 279 al. (2009), but they caution that other factors can lead to high HPC aside from nitrification, and 280 so cannot be used in isolation.

Disinfectant residual concentration is an important factor that can affect the survival and 282 growth of microorganisms including nitrifiers (Odell et al. 1996; Pintar and Slawson 2003), and 283 sites with a lower disinfectant residual will be more vulnerable to nitrification events (Yang et al. 
284 2007). However, some studies have found that AOB have long inactivation times with

285 monochloramine, so maintaining a disinfectant residual does not always prevent their growth

286 (Oldenburg et al. 2002; Wahman et al. 2009). Monitoring results in Figure 4 show that in both

287 systems there was a significant decrease in the disinfectant residual. There was some variation in 288 disinfectant residual between and within sites, and the variability was less in the Toronto system

289 compared with Waterloo. The total chlorine residual in Waterloo decreased by about one third 290 from the entrance of the distribution system (site W-WTP) to more distant sites. As mentioned

291 earlier, W-5 was the only site to use free chlorine, and therefore had a lower free chlorine

292 residual target. Combined chlorine residuals in both systems were always within the 0.25-3.0

$293 \mathrm{mg} / \mathrm{L}$ range required for distribution systems in Ontario (Ontario Ministry of the Environment

294 2006). Chlorine concentration had a statistically significant negative correlation with AOB and

295 AOA $(p<0.01)$, and HPC bacteria $(p<0.1)$ in the Toronto distribution system, and with AOB (p

$296<0.1)$ and HPC $(\mathrm{p}<0.01)$ in the Waterloo distribution system. The negative correlation between

297 total chlorine residual and microorganism abundance were expected, since previous studies have

298 shown similar findings for biofilm bacteria (Lipponen et al. 2004) and nitrifying bacteria

299 (Cunliffe 1991).

Ammonia concentration is also an important parameter, as it is the substrate for nitrifying

301 microorganisms. However, ammonia can be released by the decay of chloramine and consumed

302 by microbial activity, so its concentration in chloraminated drinking water distribution systems

303 can be difficult to interpret. In the Toronto system, average ammonia levels were similar among

304 sampling sites (Figure 5). In the Waterloo system, many sites had a high variability of ammonia

305 levels, and the concentration at site W-7 was significantly higher than at the WTP, likely due to

306 monochloramine decay. Site W-4 is a dead-end site and had the highest range of ammonia values 
307 and a lower than average chlorine residual concentration (Figure 4). Since W-5 had free-chlorine 308 instead of chloramine, it had a significantly lower ammonia concentration. In the Toronto and 309 Waterloo distribution systems, there was a decrease in the total chlorine residual and a rise in 310 ammonia at some sites in the warmer summer months, even though the chlorine residual at the 311 entrance to each distribution system remained stable (data not shown). Seasonal variations in the 312 stability of chloramines are expected, because the decay rate of monochloramine increases at 313 higher temperatures (Vikesland et al. 2001). Ammonia concentration had a weak but significant $(\mathrm{p}<0.1)$ positive correlation with 315 AOB in both distribution systems, and with AOA in the Waterloo distribution system (Table 2). 316 Even though ammonia is the substrate for the first phase of nitrification, it is unclear from 317 previous studies how ammonia affects the risk of nitrification. High ammonia concentrations 318 have been identified as a possible cause of nitrification episodes (Skadsen 1993), and Lipponen 319 et al. (2002) found that ammonia and AOB levels were correlated in drinking water distributions 320 systems (Lipponen et al. 2002). However, other studies have reported that the ammonia 321 concentration was not a significant risk factor for nitrification (Odell et al. 1996; Yang et al. 322 2007). One possible explanation for these mixed results is that the ammonia concentration 323 initially rises and then declines as nitrification progresses (Liu et al. 2005). Therefore, ammonia 324 measurements taken during different stages of a nitrification event may show opposite trends 325 (increasing or decreasing). Also, if chloraminated distribution systems are inhabited by species 326 of AOA and AOB with very low half-saturation coefficients for ammonia (Bollmann et al. 2002; 327 Martens-Habbena et al. 2009) then ammonia concentrations may not be the main growth limiting 328 factor. The results of this study indicate that the ammonia concentration may be related to the 
329

330

331

332

333

334

335

336

337

338

339

340

341

342

343

344

345

346

347

348

349

350

351

abundance of nitrifying microorganisms, but the relatively low Spearman correlation coefficients (0.21-0.29) suggest a weak relationship.

In both distribution systems, there was a negative correlation between temperature and the total chlorine residual, and a positive correlation between temperature and ammonia. This is reasonable, as monochloramine decays more quickly at higher temperatures (Vikesland et al. 2001). Nitrification has been reported across a wide range of water temperatures (Wilczak et al. 1996; Lipponen et al. 2002; Pintar et al. 2005), although higher temperatures can increase the growth rate of nitrifying bacteria (Rittmann and Snoeyink 1984; Antoniou et al. 1990). The ability of AOB to survive at low temperatures (e.g. $6^{\circ} \mathrm{C}$; Pintar and Slawson 2003) could explain why no correlation between $\mathrm{AOB}$ and temperature was observed in this study.

A rise in nitrite levels is a commonly used indicator for nitrification, since it is normally present at very low levels in distribution systems. Figure 6 shows that the average nitrite levels were below $0.01 \mathrm{mg}-\mathrm{N} / \mathrm{L}$ and there were no significant increases at sites in both systems, although they were slightly higher at most Waterloo sites compared with Toronto. As well, there was no relationship between nitrite concentrations and ammonia-oxidizing microorganisms (Table 2). The exceedance of a threshold level of nitrite can be used as an indication of nitrification, and various values have been proposed. Odell et al. (1996) suggested 0.05 mg/L $\mathrm{NO}_{2}-\mathrm{N}$, but Pintar et al. (2005) found that this was too high to serve as an effective early warning indicator. Other thresholds for identifying nitrification are $0.025 \mathrm{mg}-\mathrm{N} / \mathrm{L}$ (Fleming et al. 2005) and $0.015 \mathrm{mg}-\mathrm{N} / \mathrm{L}$ (AWWA 2006). On some sample dates, the nitrite threshold of $0.015 \mathrm{mg}-\mathrm{N} / \mathrm{L}$ was exceeded at sites T-5 and T-6 in the Toronto distribution system and at sites W-1, W-3, W-4, W-6, and W-7 in the Waterloo distribution system. However, overall, results showed that there were no large or prolonged increases in nitrite, indicating that no serious nitrification episodes 
352 occurred during the period of the sampling campaign. Pintar et al. (2005) conducted an earlier

353 study on nitrification in the Waterloo distribution system, including some sites that were sampled

354 in this study. Compared to their findings, much greater stability (less seasonal variation) of the

355 chloramine residual was observed in the present work. Even though nitrification was generally

356 well-controlled in both systems over the course of the study, the ubiquity of amo $A$ genes

357 suggests the presence of nitrifying microorganisms and the potential for nitrification if conditions 358 that limit nitrifier growth and activity are not well controlled.

\section{ACKNOWLEDGEMENTS}

The authors would like to acknowledge the tremendous support, access to facilities and data provided by Abhay Tadwalkar, Susan Atlin, David Scott and Robert Kozlowski at Toronto

363 Water, and Nancy Kodousek, Tim Walton and Alex Lee at the Region of Waterloo. We also 364 thank Shoeleh Shams at the University of Waterloo for technical assistance. Funding for this 365 project was provided by the Natural Sciences and Engineering Research Council of Canada 366 (NSERC) in the form of an Industrial Research Chair in Water Treatment at the University of 367 Waterloo. Chair partners included: Associated Engineering Group Ltd., the cities of Barrie, 368 Brantford, Guelph, Hamilton and Ottawa, Conestoga-Rovers \& Associates Limited, EPCOR 369 Water Services, GE Water \& Process Technologies Canada, Lake Huron and Elgin Area Water 370 Supply Systems, the Ontario Clean Water Agency (OCWA), the Regions of Durham, Halton, 371 Niagara and Waterloo, RAL Engineering Ltd., Toronto Water, and the Walkerton Clean Water 372 Centre. Lead author Daniel Scott was the recipient of an NSERC Canada Graduate Scholarship.

\section{REFERENCES}


375 Antoniou, P., Hamilton, J., Koopman, B., Jain, R., Holloway, B., Lyberatos, G., and Svoronos, S.

376 1990. Effect of temperature and $\mathrm{pH}$ on the effective maximum specific growth rate of

377 nitrifying bacteria. Water Res. 24(1): 97-101.

378 AWWA 2006. Fundamentals and control of nitrification in chloraminated drinking water

379 distribution systems, Manual of Water Supply Practices M56 First Edition. American Water

$380 \quad$ Works Association, Denver, CO.

381 Bollmann, A., Bär-Gilissen, M.-J., and Laanbroek, H.J. 2002. Growth at low ammonium

382 concentrations and starvation response as potential factors involved in niche differentiation

383 among ammonia-oxidizing bacteria. Appl. Environ. Microbiol. 68(10): 4751-4757.

384 Cheyne, B.M., V. Dyke, M.I., Anderson, W.B., and Huck, P.M. 2010. The detection of Yersinia

385 enterocolitica in surface water by quantitative PCR amplification of the ail and yadA genes. J.

$386 \quad$ Water Health 8(3): 487-499.

387 Cunliffe, D.A. 1991. Bacterial nitrification in chloraminated water supplies. Appl. Environ.

388 Microbiol. 57(11): 3399-3402.

389 de la Torre, J., Walker, C.B., Ingalls, A.E., Könneke, M., \& Stahl, D.A. 2008. Cultivation of a

390 thermophilic ammonia oxidizing archaeon synthesizing crenarchaeol. Environ. Microbiol.

$391 \quad 10(1): 810-818$.

392 de Vet, W.W.J.M., Dinkla, I.J.T., Muyzer, G., Rietveld, L.C., and van Loosdrecht, M.C.M. 2009.

393 Molecular characterization of microbial populations in groundwater sources and sand filters

394 for drinking water production. Water Res. 43: 182-194.

395 Fleming, K.K., Harrington, G.W., and Noguera, D.R. 2005. Nitrification potential curves: a new

396 strategy for nitrification prevention. J. Am. Water Works 97(8): 90-99. 
397 Francis, C.A., Roberts, K.J., Beman, J.M., Santoro, A.E., and Oakley, B.B. 2005. Ubiquity and 398 diversity of ammonia-oxidizing archaea in water columns and sediments of the ocean. Proc. 399 Natl. Acad. Sci. U. S. A. 102(41): 14683-14688.

400 Hach 2008 (5th ed.). Hach water analysis handbook procedures. Hach Company, USA.

401 Available from www.hach.com/water-analysis-handbook-5th-edition/product-

$402 \quad$ downloads?id=7640185976 [accessed 9 June 2014].

403 Hatzenpichler, R. 2012. Diversity, physiology, and niche differentiation of ammonia-oxidizing 404 Archaea. Appl. Environ. Microbiol. 78(21): 7501-7510.

405 Health Canada 2002. From source to tap: the multi-barrier approach to safe drinking water.

406 Available from www.hc-sc.gc.ca/ewh-semt/pubs/water-eau/tap-source-robinet/index-eng.php $407 \quad$ [accessed 9 June 2014].

408 Health Canada. 2012. Guidance on the use of heterotrophic plate counts in Canadian drinking 409 water supplies. Available from www.hc-sc.gc.ca/ewh-semt/pubs/water-eau/heterotrophic$410 \quad$ heterotrophes/index-eng.php [accessed 9 June 2014].

411 Hoefel, D., Monis, P.T., Grooby, W.L., Andrews, S., and Saint, C.P. 2005. Culture-independent 412 techniques for rapid detection of bacteria associated with loss of chloramine residual in a 413 drinking water system. Appl. Environ. Microbiol. 71(11): 6479-6488.

414 Junier, P., V. Molina, C. Dorador, O. Hadas, O. Kim, T. Junier, K. Witzel, and J.F. Imhoff. 2010. 415 Phylogenetic and functional marker genes to study ammonia-oxidizing microorganisms $416(\mathrm{AOM})$ in the environment. Appl. Microbiol. Biotechnol. 85:425-440.

417 Kasuga, I., Nakagaki, H., Kurisu, F., and Furumai, H. 2010a. Abundance and diversity of 418 ammonia-oxidizing archaea and bacteria on biological activated carbon in a pilot-scale 
drinking water treatment plant with different treatment processes. Water Sci. Technol.

420 61(12): 3070-3077.

421 Kasuga, I., Nakagaki, H., Kurisu, F., and Furumai, H. 2010b. Predominance of ammonia-

422 oxidizing archaea on granular activated carbon used in a full-scale advanced drinking water

423 treatment plant. Water Res. 44: 5039-5049.

424 LeChevallier, M.W., Lowry, C.D., and Lee, R.G. 1990. Disinfecting biofilms in a model distribution system. J. Am. Water Works 82(7): 87-99.

426

427

428

429

430

431

432

433

434

435

436

437

438

439

440

441

Lipponen, M.T., Suutari, M.H., and Martikainen, P.J. 2002. Occurrence of nitrifying bacteria and nitrification in Finnish drinking water distribution systems. Water Res. 36: 4319-4329.

Lipponen, M.T., Martikainen, P.J., Vasara, R.E., Servomaa, K., Zacheus, O., and Kontro, M.H. 2004. Occurrence of nitrifiers and diversity of ammonia-oxidizing bacteria in developing drinking water biofilms. Water Res. 38: 4424-4434.

Liu, S., Taylor, J.S., Randall, A., and Dietz, J.D. 2005. Nitrification modeling in chloraminated distribution systems. J. Am. Water Works 97(10): 98-108.

Martens-Habbena, W., Berube, P.M., Urakawa, H., de la Torre, J., and Stahl, D.A. 2009. Ammonia oxidation kinetics determine niche separation of nitrifying archaea and bacteria. Nature 461: 976-981.

National Research Council. 2006. Drinking water distribution systems: assessing and reducing risks. Committee on Public Water Supply Distribution Systems: Assessing and Reducing Risks. National Academies Press, Washington, DC.

Norton, J.M., J.J. Alzerreca, Y. Suwa, and M.G. Klotz. 2002. Diversity of ammonia monooxygenase operon in autotrophic ammonia-oxidizing bacteria. Arch. Microbiol. 177(2):139-149.Odell, L.H., Kirmeyer, G.J., Wilczak, A., Jacangelo, J.G., Marcinko, J.P., 
442

443

444

445

446

447

448

449

450

451

452

453

454

455

456

457

458

459

460

461

462

463

464

and Wolfe, R.L. 1996. Controlling nitrification in chloraminated systems. J. Am. Water Works 88(7): 86-98.

Oldenburg, P.S., Regan, J.M., Harrington, G.W., and Noguera, D.R. 2002. Kinetics of Nitrosomonas europaea inactivation by chloramine. J. Am. Water Works 94(10): 100-110.

Ontario Ministry of the Environment 2006. Procedure for disinfection of drinking water in Ontario. Available from www.ontario.ca/environment-and-energy/procedure-disinfectiondrinking-water-ontario [accessed 9 June 2014].

Pintar, K.D.M., and Slawson, R.M. 2003. Effect of temperature and disinfection strategies on ammonia-oxidizing bacteria in a bench-scale drinking water distribution system. Water Res. 37: $1805-1817$.

Pintar, K.D.M., Anderson, W.B., Slawson, R.M., Smith, E.F., and Huck, P.M. 2005. Assessment of a distribution system nitrification critical threshold concept. J. Am. Water Works 97(7): $116-129$.

Prosser, J.I., and Nicol, G.W. 2008. Relative contributions of archaea and bacteria to aerobic ammonia oxidation in the environment. Environ. Microbiol. 10(11): 2931-2941.

R Development Core Team. 2009. R: A language and environment for statistical computing. R Foundation for Statistical Computing, Vienna, Austria. Available from www.R-project.org [accessed 9 June 2014].

Rice, E.W., Scarpino, P.V., Reasoner, D.J., Logsdon, G.S., and Wild, D.K. 1991. Correlation of coliform growth response with other water quality parameters. J. Am. Water Works 83(7): $98-102$.

Rittmann, B.E., and Snoeyink, V.L. 1984. Achieving biologically stable drinking water. J. Am. Water Works 76(10): 106-114. 
465 Rittmann, B.E., Regan, J.M., and Stahl, D.A. 1994. Nitrification as a source of soluble organic 466 substrate in biological treatment. Water Sci. Technol. 30(6): 1-8.

467 Rotthauwe, J.-H., Witzel, K.-P., and Liesack, W. 1997. The ammonia monooxygenase structural 468 gene $a m o A$ as a functional marker: molecular fine-scale analysis of natural ammonia-

469 oxidizing populations. Appl. Environ. Microbiol. 63(12): 4704-4712.

Schleper, C. 2010. Ammonia oxidation: different niches for bacteria and archaea? ISME J. 4:

472

$$
1092-1094 .
$$

Skadsen, J. 1993. Nitrification in a distribution system. J. Am. Water Works 85(7): 95-103.

Standard Methods. 2005. Standard methods for the examination of water and wastewater (21st ed.). APHA, AWWA, and WEF, Washington, D.C.

van der Wielen, P.W., Voost, S., and van der Kooij, D. 2009. Ammonia-oxidizing bacteria and archaea in groundwater treatment and drinking water distribution systems. Appl. Environ. Microbiol. 75(14): 4687-4695.

Vikesland, P.J., Ozekin, K., and Valentine, R.L. 2001. Monochloramine decay in model and distribution system waters. Water Res. 35(7): 1766-1776.

Wahman, D.G., Wulfeck-Kleier, K.A., and Pressman, J.G. 2009. Monochloramine disinfection kinetics of Nitrosomonas europaea by propidium monoazide quantitative PCR and live/dead BacLight methods. Appl. Environ. Microbiol. 75(17): 5555-5562.

Wang, H., Proctor, C.R., Edwards, M.A., Pryor, M., Santo Domingo, J.W., Ryu, H., Camper, A.K., Olson, A., and Pruden, A. 2014. Microbial community response to chlorine conversion in a chloraminated drinking water distribution system. Environ. Sci. Technol. 48(18): 1062410633. 
487 Wilczak, A., Jacangelo, J.G., Marcinko, J.P., Odell, L.H., and Kirmeyer, G.J. 1996. Occurrence 488 of nitrification in chloraminated distribution systems. J. Am. Water Works 88(7): 74-85.

489 Yang, J., Harrington, G.W., Noguera, D.R., and Fleming, K.K. 2007. Risk analysis of 490 nitrification occurrence in pilot-scale chloraminated distribution systems. J. Water Supply $491 \quad$ Res. Technol. AQUA 56(5): 293-311.

492 Zhang, Y., and Edwards, M. 2009. Accelerated chloramine decay and microbial growth by

493 nitrification in premise plumbing. J. Am. Water Works 101(11): 51-62.

494 Zhang, Y., Love, N., and Edwards, M. 2009. Nitrification in drinking water systems. Crit. Rev. 495 Environ. Sci. Technol. 39: 153-208.

496 
497 TABLES

498 Table 1. Average water quality values measured at the entrance to each distribution system

\begin{tabular}{l|c|c}
\hline \multicolumn{1}{c|}{ Parameter } & $\begin{array}{c}\text { Toronto } \\
\text { (mean } \pm \text { standard deviation) }\end{array}$ & $\begin{array}{c}\text { Waterloo } \\
\text { (mean } \pm \text { standard deviation) }\end{array}$ \\
\hline Source & Lake Ontario & $\begin{array}{c}\text { Surface water blended with } \\
\text { groundwater }\end{array}$ \\
$\mathrm{pH}$ & $7.5 \pm 0.2$ & $7.5 \pm 0.2$ \\
Temperature $\left({ }^{\circ} \mathrm{C}\right)$ & $10 \pm 2$ & $12 \pm 6$ \\
$\begin{array}{l}\text { Dissolved organic carbon } \\
(\mathrm{mg} / \mathrm{L})\end{array}$ & $2.64 \pm 0.86$ & $3.57 \pm 1.32$ \\
Conductivity $(\mu \mathrm{S} / \mathrm{cm})$ & $316 \pm 34$ & $706 \pm 62$ \\
Total chlorine $\left(\mathrm{mg}-\mathrm{Cl}{ }_{2} / \mathrm{L}\right)$ & $1.28 \pm 0.11$ & $1.47 \pm 0.12$ \\
Ammonia $(\mathrm{mg}-\mathrm{N} / \mathrm{L})$ & $0.13 \pm 0.10$ & $0.15 \pm 0.05$ \\
Nitrate $(\mathrm{mg-N} / \mathrm{L})$ & $0.43 \pm 0.12$ & $3.48 \pm 0.52$ \\
Nitrite $(\mathrm{mg}-\mathrm{N} / \mathrm{L})$ & $0.001 \pm 0.002$ & $0.004 \pm 0.004$ \\
\hline
\end{tabular}


500 Table 2. Correlation coefficient values $(p)$ for parameters in each full-scale distribution system

\begin{tabular}{|c|c|c|c|c|c|c|c|}
\hline & \multicolumn{4}{|c|}{ Toronto } & \multicolumn{3}{|c|}{ Waterloo } \\
\hline & AOB & AOA & HPC & Temp & AOB & AOA & HPC \\
\hline AOB & & -0.01 & $0.51 * *$ & 0.18 & & $0.71 * *$ & $0.58 * *$ \\
\hline AOA & & & -0.06 & $0.22 *$ & & & 0.15 \\
\hline Total chlorine & $-0.45^{* *}$ & $-0.28 * *$ & $-0.21 *$ & $-0.23 *$ & $-0.25 *$ & 0.01 & $-0.50 * *$ \\
\hline DOC & 0.04 & 0.14 & -0.15 & $0.58 * *$ & -0.07 & 0.02 & 0.02 \\
\hline Ammonia & $0.21 *$ & 0.13 & 0.06 & $0.51 * *$ & $0.27 *$ & $0.29 *$ & 0.16 \\
\hline Nitrite & 0.12 & 0.06 & 0.17 & 0.2 & 0.17 & 0.15 & -0.03 \\
\hline \multicolumn{8}{|c|}{$*$ significant at $\mathrm{p}<0.1 ; * *$ significant at $\mathrm{p}<0.01$} \\
\hline & & & & & & & \\
\hline & & & & & & & \\
\hline \multicolumn{8}{|c|}{ Table 3. Nitrifiers measured using a culture-based (presence/absence) method } \\
\hline \multicolumn{4}{|c|}{ Toronto } & \multicolumn{4}{|c|}{ Waterloo } \\
\hline \multicolumn{2}{|r|}{ Site } & \multicolumn{2}{|c|}{ Nitrifiers } & \multicolumn{2}{|c|}{ Site } & \multicolumn{2}{|c|}{ Nitrifiers } \\
\hline \multicolumn{2}{|c|}{ T-WTP } & \multicolumn{2}{|c|}{ Absent } & \multicolumn{2}{|c|}{ W-WTP } & \multicolumn{2}{|c|}{ Present } \\
\hline \multicolumn{2}{|r|}{$\mathrm{T}-1$} & \multicolumn{2}{|c|}{ Present } & \multicolumn{2}{|c|}{$\mathrm{W}-1$} & \multicolumn{2}{|c|}{ Present } \\
\hline & $\mathrm{T}-2$ & \multicolumn{2}{|c|}{ Present } & \multicolumn{2}{|c|}{$\mathrm{W}-2$} & \multicolumn{2}{|c|}{ Present } \\
\hline & $\mathrm{T}-3$ & \multicolumn{2}{|c|}{ Absent } & \multicolumn{2}{|c|}{$\mathrm{W}-3$} & \multicolumn{2}{|c|}{ Present } \\
\hline & $\mathrm{T}-4$ & \multicolumn{2}{|c|}{ Present } & \multicolumn{2}{|c|}{$\mathrm{W}-4$} & \multicolumn{2}{|c|}{ Present } \\
\hline & $\mathrm{T}-5$ & \multicolumn{2}{|c|}{ Present } & & -5 & & sent \\
\hline & $\mathrm{T}-6$ & & sent & & -6 & & sent \\
\hline & & & & & -7 & & sent \\
\hline
\end{tabular}




\section{FIGURE CAPTIONS}

Figure 1. Concentrations of bacterial amoA gene copies in the Toronto and Waterloo distribution systems. Significant differences between the water treatment plant (T-WTP and W-WTP) and distribution system sites are marked as $*(n=12$ for each Toronto site and $n=9$ for each Waterloo site).

Figure 2. Concentrations of archaeal amoA gene copies in the Toronto and Waterloo distribution systems. Significant differences between the water treatment plant (T-WTP and W-WTP) and distribution system sites are marked as * $(n=12$ for each Toronto site and $n=9$ for each Waterloo site).

Figure 3. First flush HPC levels at each site in the Toronto and Waterloo distribution systems. Significant differences between the water treatment plant (T-WTP and W-WTP) and distribution system sites are marked as * $(n=12$ for each Toronto site and $n=9$ for each Waterloo site).

Figure 4. Total chlorine residual concentrations at sample locations in each distribution system. Significant differences between the water treatment plant (T-WTP and W-WTP) and distribution system sites are marked as * $(n=12$ for each Toronto site and $n=9$ for each Waterloo site).

Figure 5. Ammonia concentrations at sample locations in each distribution system. Significant differences between the water treatment plant (T-WTP and W-WTP) and distribution system sites are marked as $*(\mathrm{n}=12$ for each Toronto site and $\mathrm{n}=9$ for each Waterloo site).

Figure 6. Nitrite concentrations at sample locations in each distribution system $(\mathrm{n}=12$ for each Toronto site and $\mathrm{n}=9$ for each Waterloo site). 


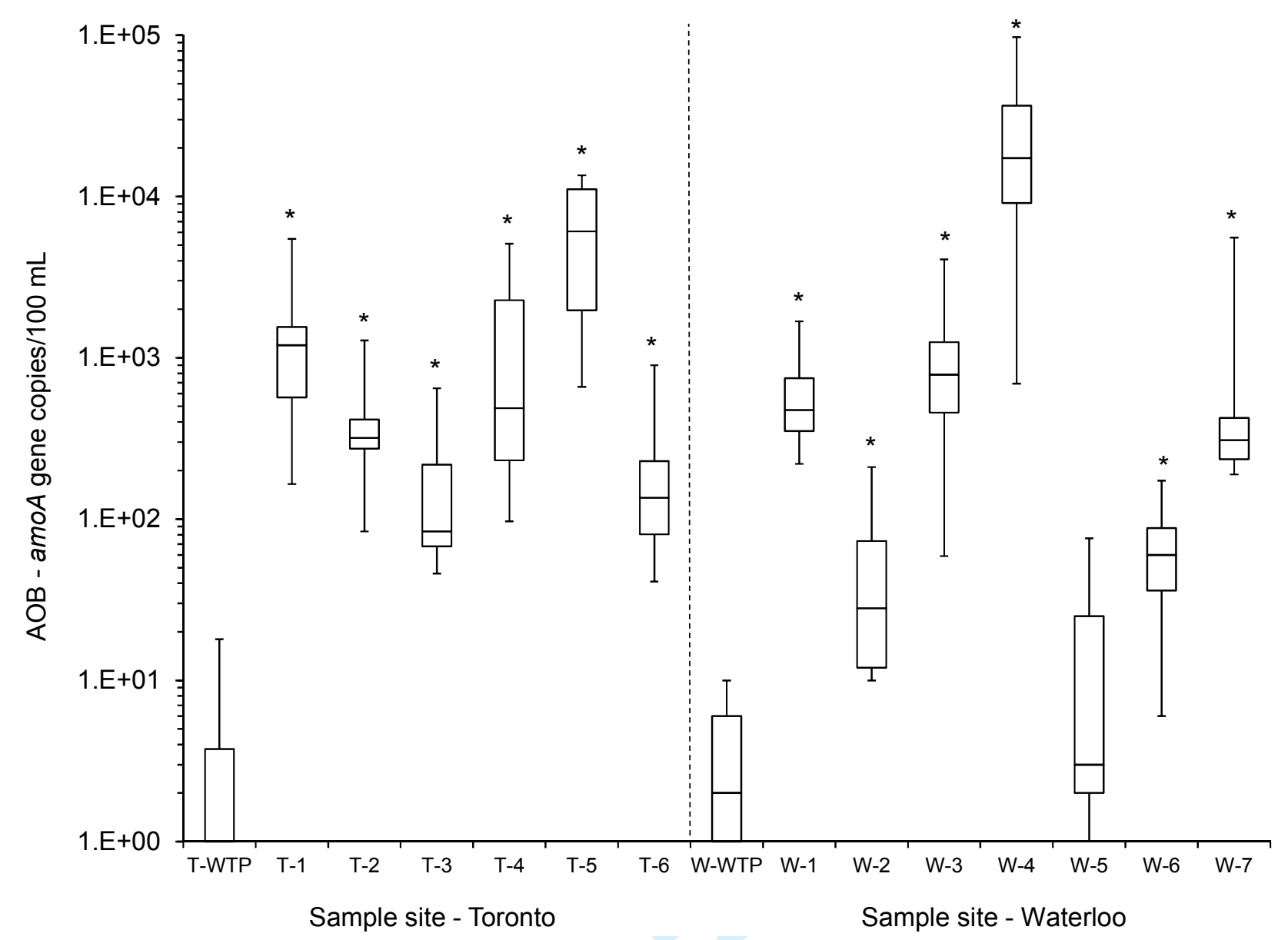




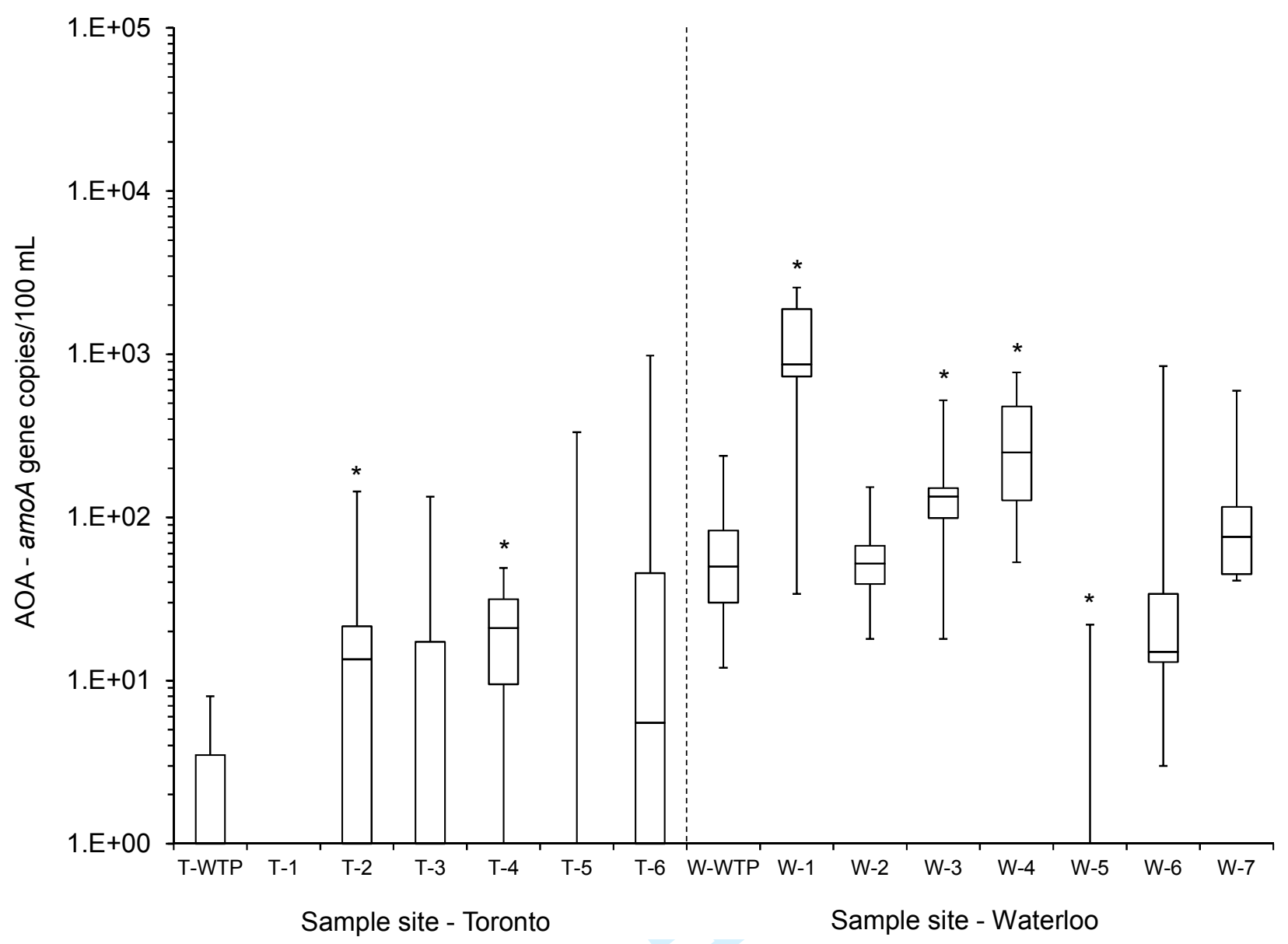




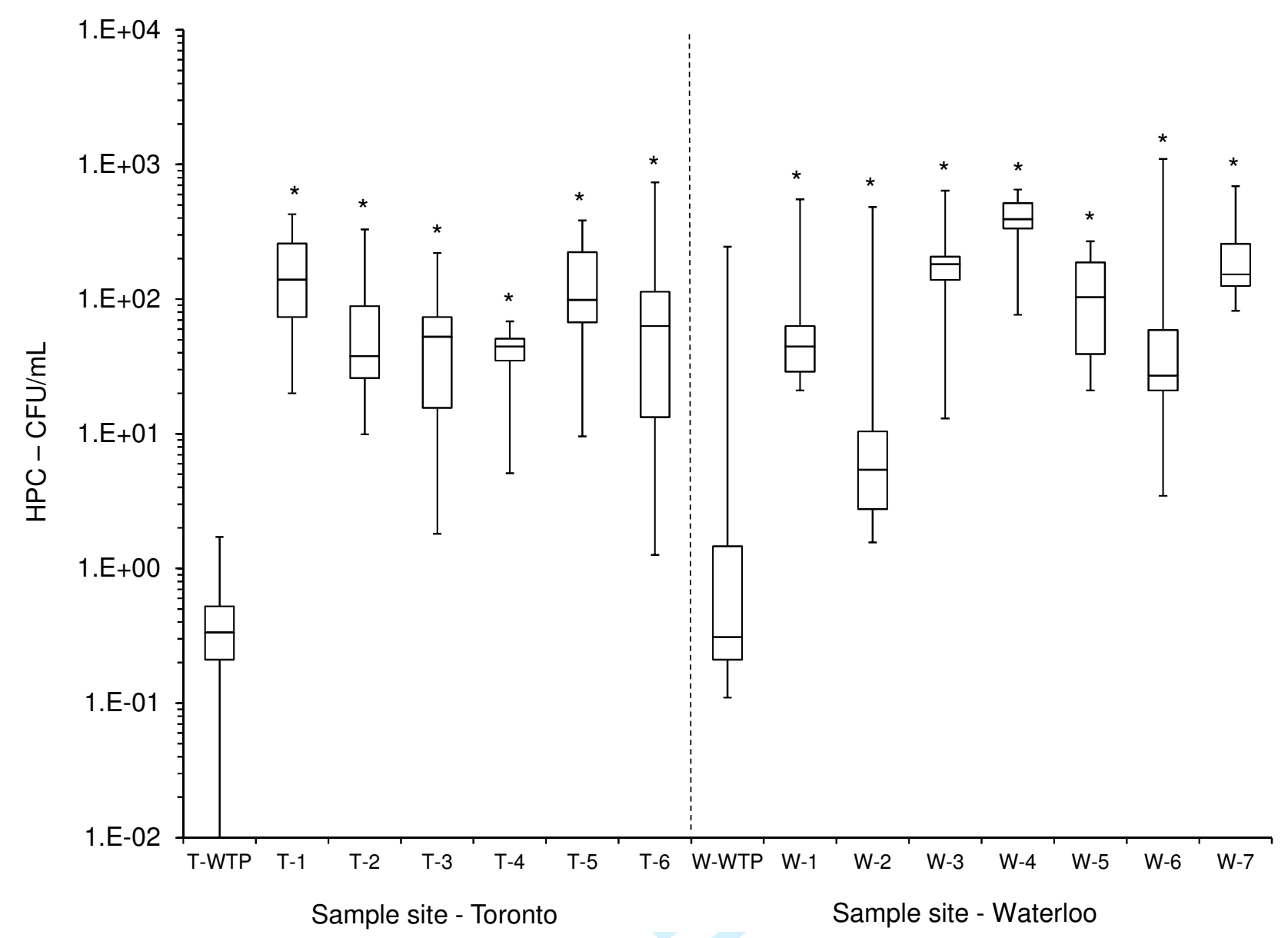




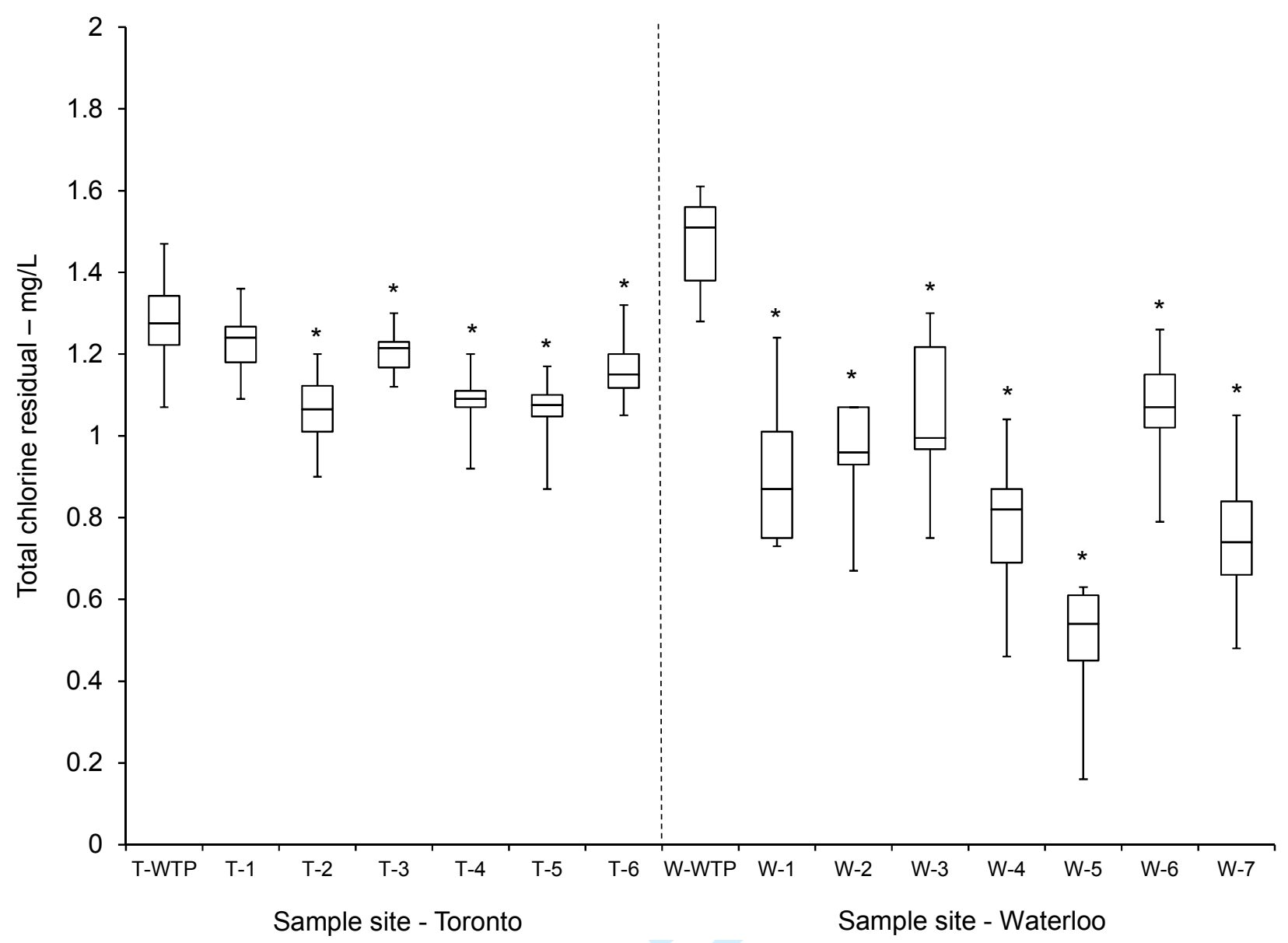




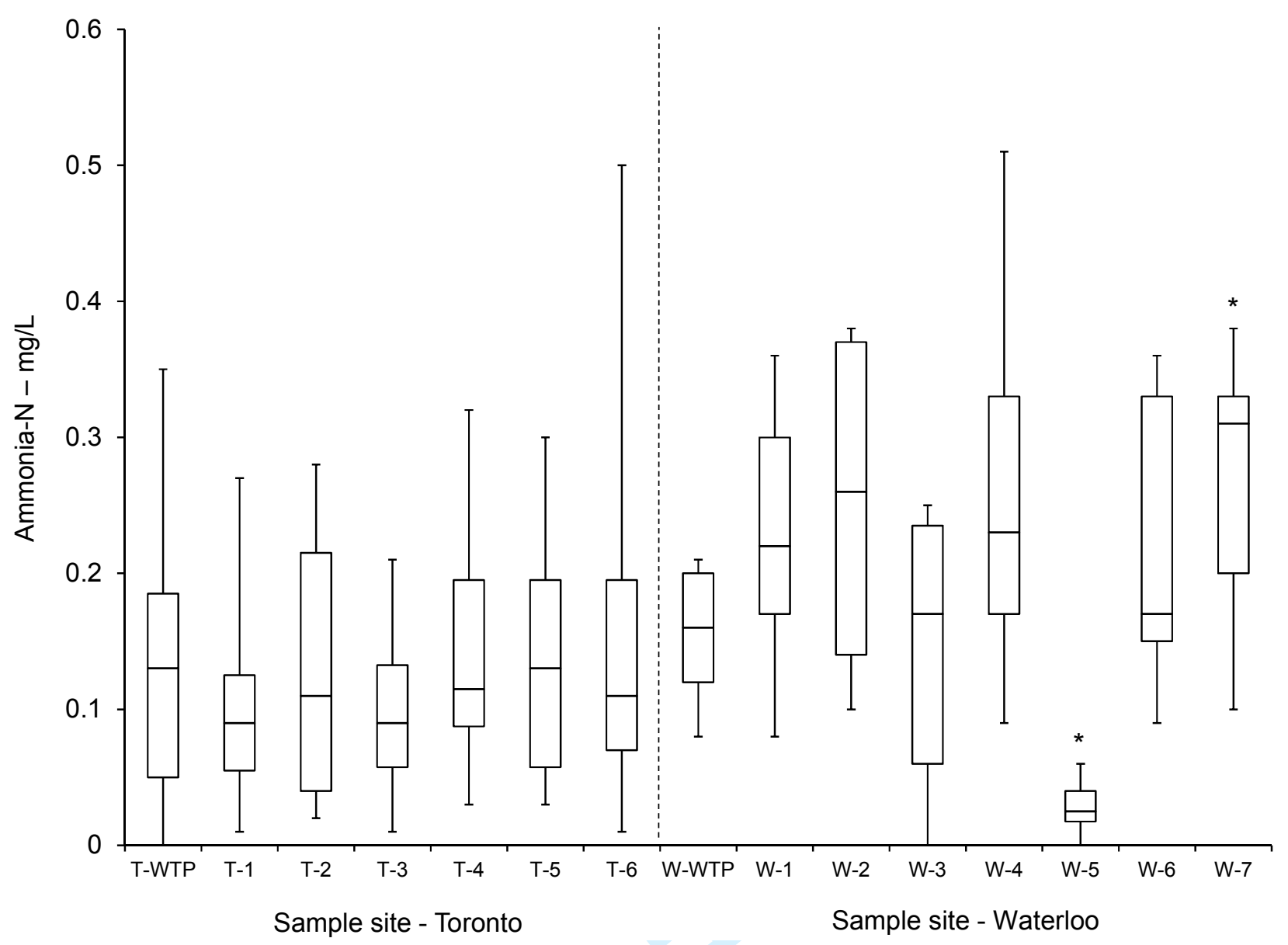




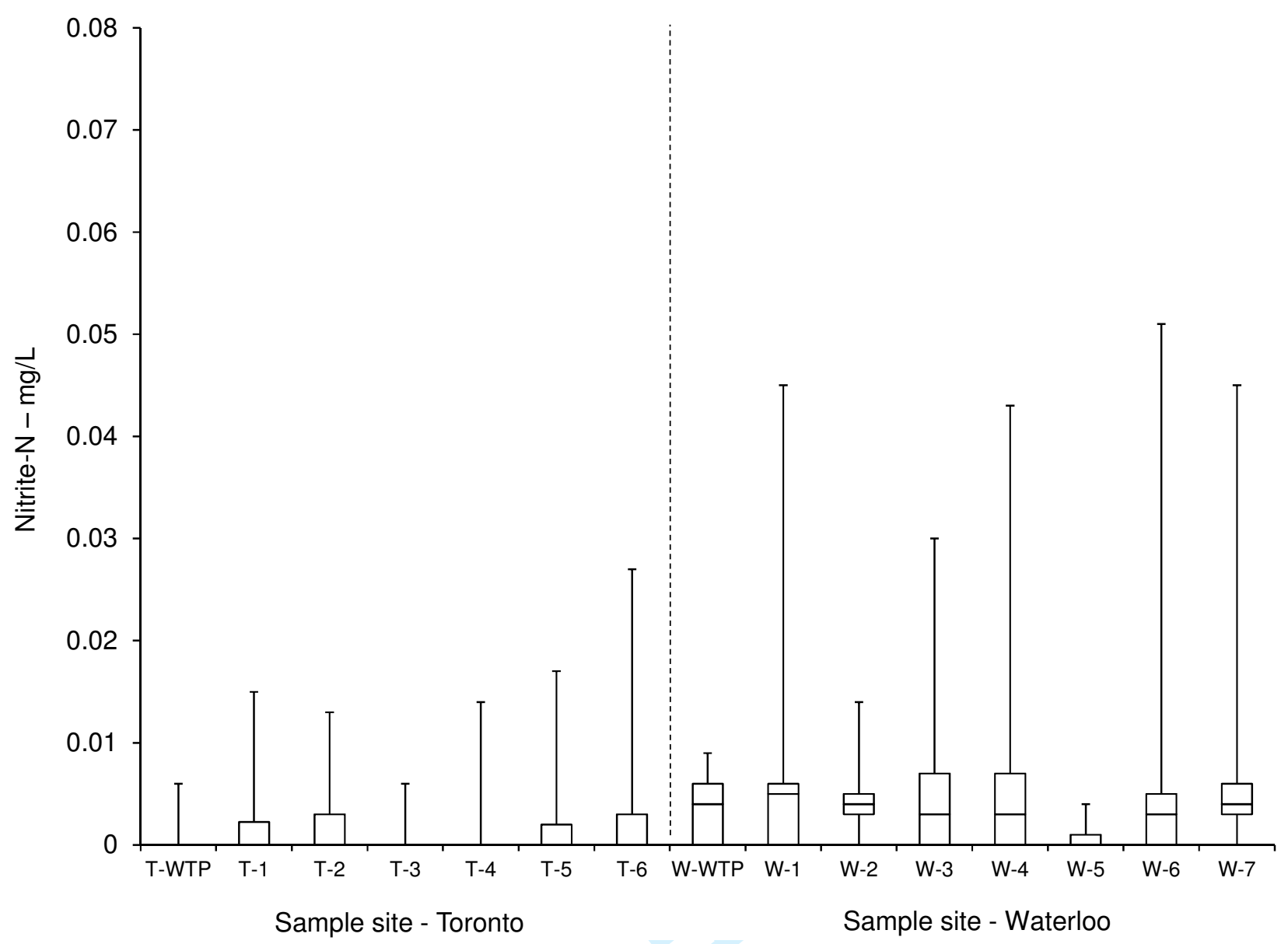

